\title{
Desenvolvimento de pães funcionais enriquecidos com extrato da casca de jaboticaba (Myrciaria cauliflora).
}

\section{Beatriz S. Nunes*, Maurício A. Rostagno}

\section{Resumo}

O intuito do projeto foi analisar o enriquecimento de pães com diferentes concentrações (1\%, 2,5\%, $5 \%$ e $7,5 \%)$ de extrato da casca da jabuticaba (Myrciaria cauliflora), a fim de torna-ló um alimento funcional. Foi realizado o processo de liofilização das cascas de jabuticaba e seu extrato, sendo esse o material que foi substituido pela farinha de trigo dos pães. Em seguida, foi feito análises de compostos fenólicos e capacidade antioxidante através de FRAP e ABTS.

Palavras-chave: compostos fenólicos; casca da jabuticaba (Myrciaria cauliflora); pão; propriedades funcionais

\section{Introdução}

As frutas são conhecidas por serem fontes de vitaminas, minerais e fibras, tendo elevada importância nutricional. Nelas podemos encontrar os compostos bioativos que são metabólitos secundários de plantas e estão associados à prevenção de doenças cardiovasculares, neurodegenerativas, câncer, entre outras, devido a sua alta capacidade antioxidante ${ }^{1}$. Os polifenóis constituem um dos maiores grupos de compostos bioativos, além de serem substâncias que os animais não conseguem produzir ${ }^{1}$. Entre os vegetais, os quais são fontes destes compostos, está a jabuticaba ${ }^{2}$. Ela é um fruto brasileiro e sua casca possui elevadas concentrações de compostos fenólicos como as proantocianidinas, os elagitaninos e as antocianinas, que se destacam por sua capacidade antioxidante, antiinflamatória e atuam na regulação do metabolismo da glicose e dos lipídios. Entre 35 frutas brasileiras, a jabuticaba apresenta as maiores concentrações de ácido elágico livre e total ${ }^{3,4}$.

Sua casca representa aproximadamente metade do fruto, que em sua maioria é descartada ${ }^{2}$. Em busca de melhorar o aproveitamento deste resíduo, o projeto presente utilizou o extrato da casca de jabuticaba para enriquecer pães, a fim de os tornar um alimento funcional e analisar sua quantidade de fenólicos totais, capacidade antioxidante e sua estabilidade após a cocção.

\section{Resultados e Discussão}

Os resultados obtidos foram a partir da adição de diferentes concentrações, sendo $1 \%, 2,5 \%, 5 \%$ e $7,5 \%$ do extrato da casca de jabuticaba em pães, mostrando que a quantidade de fenólicos e capacidade antioxidante se mantém após terem passado pelo processamento térmico.

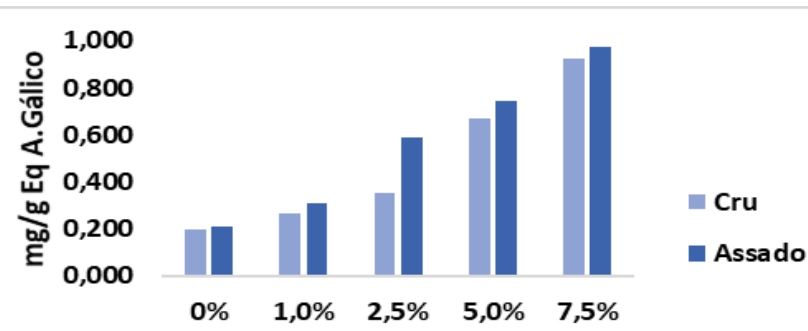

\% de substituição de extrato de pão feito com a casca de jabuticaba

Figura 1. Concentração de fenólicos totais nos pães.

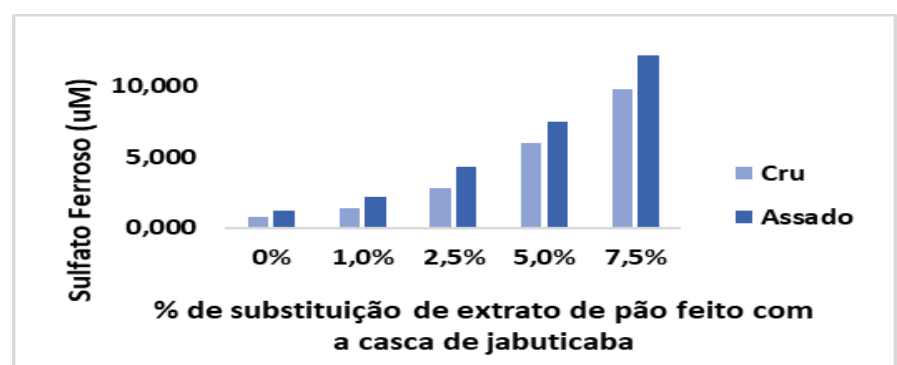

Figura 2. Capacidade antioxidante por FRAP nos pães.

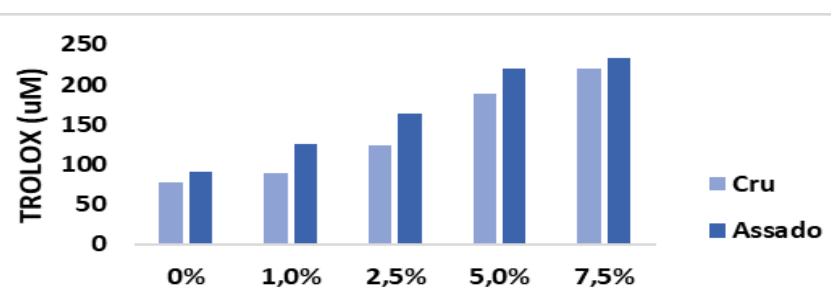

\% de substituição de extrato de pão feito com a casca de jabuticaba

Figura 3. Capacidade antioxidante por ABTS nos pães.

\section{Conclusões}

Após a realização das análises dos pães crus e assados observou-se que a quantidade de compostos fenólicos e a capacidade antioxidante se mantiveram e teve um aumentou nos pães assados, este fato pode ter ocorrido por conta da perda de água no processo de cocção, concentrando ainda mais a quantidade dos compostos bioativos. Desse modo, é possível relatar que a incorporação do extrato da casca da jabuticaba foi efetiva e tem potencial para trazer benefícios à saúde.

\section{Agradecimentos}

Agradeço a meu orientador Maurício A. Rostagno, a minha coorientadora Rosângela M. N. Bezerra e todos do LABMAS, além da bolsa concedida pela PIBIC/CNPq.

1- HALLIWELL, Barry; GUTTERIDGE, John M.c.. Free Radicals in Biology and Medicine. 5. ed. United Kingdom: Oxford University Press, 2015.

2- SASSO, Simone Aparecida Zolet. PROPAGAÇÃo VEGETATIVA DE JABUTICABEIRA. 2009. 64 f. Tese (Doutorado) - Curso de Agronomia, Universidade Tecnológica Federal do Paraná, Pato Branco, 2009.

3- OLIVEIRA, Antônio Luís de et al, Caracterização tecnológica de jabuticabas 'Sabará' provenientes de diferentes regiões de cultivo. Rev. Bras. Frutic., Jaboticabal , v. 25, n. 3, p. 397-400, Dec. 2003.

4- MOURA, Márcio Hercules Caldas. Avaliação do efeito de extratos ricos em compostos fenólicos da jabuticaba-sabará ((Plinia janoticaba (Vell.) Berg) na prevenção da obesidade e do diabetes mellitus tipo 2. 2016. 20 f. Monografia (Especialização) - Curso de Ciência dos Alimentos, Universidade de São Paulo, São Paulo, 2016. 